\title{
Keeping the balance in NAD metabolism
}

$\emptyset_{\text {yvind Strømland }}{ }^{1}$, Marc Niere ${ }^{1}$, Andrey A. Nikiforov ${ }^{2,3}$, Magali R. VanLinden ${ }^{1}$, Ines Heiland ${ }^{4}$, and Mathias Ziegler ${ }^{1 *}$

${ }^{1}$ Department of Biomedicine, University of Bergen, 5009 Bergen, Norway

${ }^{2}$ Institute of Cytology, Russian Academy of Sciences, 194064 St. Petersburg, Russia

${ }^{3}$ Institute of Nanobiotechnologies, Peter the Great St. Petersburg Polytechnic University, 195251 St. Petersburg, Russia

${ }^{4}$ Department of Arctic and Marine Biology, UiT The Arctic University of Norway, 9037 Troms $\varnothing$, Norway

* To whom correspondence should be addressed (email: Mathias.Ziegler@uib.no)

\section{Keywords}

Nicotinamide adenine dinucleotide, NAD, PARP, NMNAT, sirtuins, SIRT, SARM1, Nicotinamide riboside, Nicotinamide mononucleotide, Neuronal degeneration, Wld $_{s}$, Wallerian degeneration, NAD transporter, NAD replenishment, NAD supplementation, NAD biosynthesis, ADP-ribosylation

\section{Abbreviations}

ADPR, ADP-ribose; ARH1, ADP-ribosyl-acceptor hydrolase 1; ARTC, clostridial toxin-like ADPribosyltransferase; ARTD, diphtheria toxin-like ADP-ribosyltransferases; cADPR, cyclic ADP-ribose; Nam, Nictotinamide; NA, Nicotinic acid; NAAD, Nicotinic acid adenine dinucleotide; NAADP, Nicotinic acid adenine dinucleotide phosphate; NAD, Nicotinamide adenine dinucleotide; NADP, Nicotinamide adenine dinucleotide phosphate; NAMN, Nicotinic acid mononucleotide; NamPRT, Nicotinamide phosphoribosyltransferase; NAPRT, Nicotinic acid phosphoribosyltransferase; NAR, Nicotinic acid riboside; NMN, Nicotinamide mononucleotide; NMNAT, Nicotinamide mononucleotide adenelyltransferase; NR, Nicotinamide riboside; NRK, Nicotinamide riboside kinase; PAR, Poly-ADPribose; PARG, Poly-ADP-ribose glycohydrolase; PARP, Poly-ADP-ribose polymerase; Pyruvate dehydrogenase complex (PDC) QA, Quinolinic acid; QAPRT, Quinolinic acid phosphoribosyltransferase; SARM1, Sterile alpha and Toll/interleukin-1 receptor motif containing 1; TARG1, Terminal ADP-Ribose Protein Glycohydrolase 1; Wld , Wallerian degeneration slow.

\section{Abstract}

Research over the last few decades has extended our understanding of nicotinamide adenine dinucleotide (NAD) from a vital redox carrier to an important signalling molecule that is involved in the regulation of a multitude of fundamental cellular processes. This includes DNA repair, cell cycle 
regulation, gene expression and calcium signalling, in which NAD is a substrate for several families of regulatory proteins, such as sirtuins and ADP-ribosyltransferases. At the molecular level, NADdependent signalling events differ from hydride transfer by cleavage of the dinucleotide into an ADPribosyl moiety and nicotinamide. Therefore, non-redox functions of NAD require continuous biosynthesis of the dinucleotide. Maintenance of cellular NAD levels is mainly achieved by nicotinamide salvage, yet a variety of other precursors can be used to sustain cellular NAD levels via different biosynthetic routes.

Biosynthesis and consumption of NAD are compartmentalised at the subcellular level, and currently little is known about the generation and role of some of these subcellular NAD pools. Impaired biosynthesis or increased NAD consumption are deleterious and associated with ageing and several pathologies. Insults to neurons lead to depletion of axonal NAD and rapid degeneration, partial rescue can be achieved pharmacologically by administration of specific NAD precursors. Restoring NAD levels by stimulating biosynthesis or through supplementation with precursors also produces beneficial therapeutic effects in several disease models. In this review, we will briefly discuss the most recent achievements and the challenges ahead in this diverse research field.

\section{Introduction}

NAD is an important redox carrier mediating hydride transfer in oxido-reductive metabolic pathways, including the citric acid cycle, amino acid catabolism, $\beta$-oxidation of fatty acids and the urea cycle. In addition to its role as a redox carrier, NAD is an important signalling molecule involved in many vital cellular processes. For example, sirtuins are a class of NAD-dependent protein deacylases that display catalytic activity on a broad range of substrates (1) and regulate important processes such as cell cycle progression, circadian rhythm, genome stability, transcription, ageing, mitochondrial biogenesis and apoptosis $(2,3)$. Sirtuin-mediated deacylation is coupled with cleavage of NAD into nicotinamide (Nam) and ADP-ribose (ADPR). The most common case is the deacetylation of proteins, where the leaving acetyl moiety is transferred onto ADPR, thereby forming O-acetyl-ADP-ribose (4) (Figure 1).

Of the NAD-dependent protein modifications, ADP-ribosylation was discovered first (5). In the reaction, one (mono-ADP-ribosylation) or several (poly-ADP-ribosylation) ADPR moieties from NAD are transferred onto acceptor proteins, releasing Nam (Figure 1). Two families of enzymes are responsible for ADP-ribosylation: diphtheria toxin-like ADP-ribosyltransferases (referred to as ARTDs or PARPs) and clostridial toxin-like ADP-ribosyltransferase (ARTCS) (6). ADP-ribosylation is tightly regulated and, like most other post-translational modifications, reversible. The cleavage of poly-ADPribose is largely performed by poly-ADP-ribose glycohydrolase (PARG), which cleaves the O-glycosidic bonds within polymers. However, PARG cannot remove the terminal ADPR moiety or reverse mono- 
ADP-ribosylation, which instead is eliminated by enzymes such as ADP-ribosyl-acceptor hydrolase 1 (ARH1) and Terminal ADP-Ribose Protein Glycohydrolase 1 (TARG1) (7,8). ADP-ribosylation plays a role in innate immunity, DNA repair, transcription, cell cycle progression, energy metabolism, cell-cell interaction and a plethora of other processes $(9,10)$.

In addition to its role in protein post-translational modifications $N A D(P)$ is a precursor of nicotinic acid adenine dinucleotide phosphate (NAADP), cyclic ADP-ribose (cADPR) and ADPR, which are key regulators of calcium-signalling and synthesised by the multifunctional ADP-ribosyl cyclase CD38 and its homolog CD157 (Figure 1) (11,12). NAADP and cADPR stimulate release of calcium from endogenous stores, whereas ADPR triggers entry of calcium from the extracellular space (11,13-15). Maintenance of NAD-dependent signalling processes where NAD is cleaved hinges on a constant resupply of the dinucleotide.

\section{Metabolism of NAD in humans}

Under basal conditions, NAD-dependent protein deacetylation and ADP-ribosylation account for two thirds of net NAD consumption. The half-life of NAD in vivo varies between 15 min to 15 hours depending on the tissue, highlighting the importance of continuous re-synthesis of the dinucleotide (16). NAD is generated from dietary precursors or recycled from NAD degradation products. The precursors, collectively known as vitamin B3, are Nam and nicotinic acid (NA) as well as the nucleosides nicotinamide riboside (NR) and nicotinic acid riboside (NAR) $(17,18)$. Additionally, quinolinic acid (QA), a product generated from tryptophan catabolism in the kynurenine pathway, is utilised to generate NAD de novo (Figure 1) (19).

In mammals, the most prominent pathway of NAD synthesis is the salvage pathway in which Nam, a by-product of both NAD dependent deacylation and ADP-ribosylation, is recycled to regenerate NAD. Nam is converted to nicotinamide mononucleotide (NMN) by nicotinamide phosphoribosyltransferase (NamPRT). NMN is also produced when NR is phosphorylated by nicotinamide riboside kinase (NRK). In the final step of NAD biosynthesis, NMN is adenylylated by nicotinamide mononucleotide adenylyltransferase (NMNAT) to form NAD $(20,21)$. In the PreissHandler pathway, nicotinic acid adenine dinucleotide (NAMN) is synthesised from NA by nicotinic acid phosphoribosyltransferase (NAPRT), NAMN is also generated when NAR is phosphorylated by NRK. The subsequent reaction catalysed by NMNAT yields nicotinic acid adenine dinucleotide (NAAD), which is then amidated to NAD by NAD synthetase (NADS) $(22,23)$. De novo synthesis of NAD includes the conversion of QA to NAMN by quinolinic acid phosphoribosyltransferase (QAPRT) which is then further used in the Preiss-Handler pathway (Figure 1) (19). Recently it has been demonstrated that NR and NAR generated by dephosphorylation of the corresponding mononucleotides can be 
secreted from cells, suggesting that different cell types can help maintain each other's NAD pools (24). NAD biosynthesis and NAD dependent signalling reactions are both compartmentalized in the eukaryotic cell, a fact that raises topological questions that remain unanswered.

\section{Compartmentalisation of NAD biosynthesis and metabolism}

NAD-dependent metabolic pathways predominate in the mitochondria and cytosol, which, along with the nucleus, are also the major compartments with non-redox functions of this dinucleotide. Basal cellular NAD consumption was reported to depend particularly on nuclear poly-ADPribosylation by PARPs/ARTDs $1 / 2$ and on sirtuins 1/2-mediated protein deacetylation in the nucleus and the cytosol (16). Mitochondria contain three sirtuin isoforms (Figure 2), of which SIRT3 is the major protein deacetylase (25), whereas SIRT5 preferentially removes the acyl-groups of succinylated, malonylated and glutarylated proteins $(26,27)$. SIRT4 is a bifunctional enzyme catalyzing both mono-ADP-ribosylation (28) and protein deacylation $(29,30)$. As demonstrated for the mitochondrial Pyruvate dehydrogenase complex (PDC), the deacylation activity of SIRT4 is most efficient on lipolylated and biotinylated proteins $(29,30)$.

A biosensor system based on immunodetection of poly-ADP-ribose (PAR) as readout allowed for indirect visualisation of NAD also in peroxisomes, the endoplasmic reticulum and the Golgi apparatus (31). However, the role and importance of these organellar NAD pools remain poorly characterised. Since biological membranes are impermeable for pyridine nucleotides, the presence of NAD in various subcellular compartments raises the question of how these individual pools are generated and maintained, and whether they are segregated or exchangeable.

The human genome harbours three genes encoding NMNAT isozymes, that differ in catalytic properties, oligomerisation state and subcellular localisation, namely, to the nucleus (NMNAT1) $(32,33)$, the cytosolic face of the Golgi (NMNAT2) $(34,35)$ and the mitochondria (NMNAT3) (Figure 2) (33). This distinct subcellular distribution overlaps with the localisation of major NAD consuming pathways. However, it differs from the nuclear-cytosolic localisation common to all other NAD biosynthetic enzymes (36). Moreover, with the exception of the two NRK isozymes, all other enzymes of NAD biosynthesis are encoded by single genes.

The subcellular location of NMNAT3 intuitively suggests that this isozyme is responsible for the synthesis of NAD in mitochondria, yet a mechanism for the supply of the substrate NMN into this organelle is elusive. The apparent absence of a pathway for autonomous NMN biosynthesis in mitochondria (37) was suggested to be bypassed by import of the mononucleotide from the cytosol (36), but a mitochondrial carrier for NMN awaits identification. Several recent studies challenge a 
vital role of NMNAT3. For example, $\mathrm{Nmnat}^{-{ }^{--}}$mice are viable and the absence of an NMNAT3 appears to affect metabolic functions rather in the cytosol than in mitochondria (38). NAD levels in skeletal muscle, which are elevated in transgenic Nmnat3 mice (39), are hardly affected in Nmnat3 ${ }^{-1-}$ mice (40). These findings suggest alternative mechanisms to compensate for the lack of NMNAT3. A mitochondrial carrier for NAD has been identified in yeast (41) and plants (42), and studies performed using isotopically labelled precursors (37) and a genetically encoded fluorescent NAD biosensor (43) provided supporting evidence for mitochondrial import of NAD, which may be generated by NMNAT2 in the cytosol (Figure 2). In humans, direct import of NAD through a biological membrane has so far only been suggested for peroxisomes. SLC25A17, a member of the solute carrier family of membrane transport proteins was shown to be able to carry NAD into reconstituted liposomes, indicating that it is a peroxisomal NAD carrier (44). The identity of a human mitochondrial NAD transporter remains unknown.

Embryonic lethality of both NMNAT1 ${ }^{--}(45)$ and NMNAT2 ${ }^{--}$(46) mice implies important nonredundant roles for these two isozymes in the nucleus and the cytosol, and recent reports challenge the hypothesis that the nuclear membrane does not provide a diffusion barrier for pyridine nucleotides. For instance, studies performed with a fluorescent NAD biosensor indicated that the selective downregulation of cytosolic NMNAT2 does not affect the nuclear NAD pool (43). Using the same experimental tool, Ryu et al. suggested a distinct segregation of these two NAD pools related to a biological function. They demonstrated that the PARP1-dependent activation of genes involved in adipocyte differentiation is regulated by restricting NMN availability for nuclear NAD biosynthesis by NMNAT1 through stimulation of cytosolic NMNAT2 expression (47).

\section{The role of NAD metabolism in maintaining axonal integrity}

NAD metabolism has emerged as a key regulator of axonal degeneration. In injured axons, ATP loss and morphological degeneration are preceded by rapid NAD depletion $(48,49)$. The seminal discovery of the mouse mutant Wallerian degeneration slow $\left(W / d_{s}\right)$, whose peripheral nerves remain intact for 14 days following axotomy (Figure 3), led to the realisation that axonal degeneration is a regulated process. The underlying mutation for the expression of the Wld $\mathrm{W}_{\mathrm{s}}$ protein in these mice consists of a 85 $\mathrm{kb}$ - tandem triplication on chromosome 4 which leads to the generation of a chimeric protein composed of the $70 \mathrm{~N}$-terminal residues from the ubiquitin ligase Ufd2a and full length NMNAT1 (50).

The protective mechanism of the Wld protein is not fully understood. In neurons, Wld predominantly localises to the nucleus where it activates SIRT1, leading to changes in gene expression (51). However, a small proportion of $\mathrm{Wld}_{\mathrm{s}}$ is found in axons and the presence and activity 
of this axonal pool affords protection against degeneration (52). Furthermore, the neuroprotective properties of a recombinant NMNAT1 fused to an axonal targeting peptide (53), along with the finding that NAD depletion triggers axonal degeneration (54), provided supporting evidence that the key to axonal protection is the NMNAT1 activity by the $\mathrm{Wld}_{\mathrm{s}}$ protein.

Recent work has established NMNAT2 as a critical factor for maintaining axonal integrity. In neurons, NMNAT2 is subject to continuous anterograde transport necessitated by the short half-life of the enzyme. Blocking this transport triggers Wallerian degeneration (Figure 3$)(55,56)$. Due to the protective effect of Wld in several disease models (57-59), the expression level of NMNAT2 has been proposed to play a role in several neurodegenerative disorders. Indeed, reduced levels of NMNAT2 have been linked to decreased cognitive function in humans and taupathy in mice $(60,61)$. However, the role of NMNAT2 in these conditions is not understood.

The mechanisms underlying axonal degeneration downstream of NMNAT2 are currently debated and two different models have been proposed (Figure 3). The first model suggests maintenance of axonal NAD to be essential for survival, yet both in vitro and in vivo studies performed with $\mathrm{CD} 38^{-\%}$ and $\mathrm{PARP}^{-/}$models excluded a contribution of these NAD-consuming enzymes in axonal degeneration (54). Recently, SARM1 (sterile alpha and Toll/interleukin-1 receptor motif containing 1) was identified as a central executioner of the axon degeneration pathway which is essential for NAD depletion in injured neurons $(62,63)$. In Sarm $1^{-1}$ mice, axonal degeneration is delayed by several weeks following injury. In addition, these mice display improved outcomes after the induction of peripheral neuropathy and traumatic brain injury $(62,64,65)$. Mechanistically, SARM1-mediated NAD depletion was revealed by the discovery of the SARM1 TIR domain as a member of an ancient class of NAD glycohydrolases $(66,67)$. SARM1 NAD glycohydrolase activity is driven by dimerisation of its TIR domain, and forced dimerisation induces catastrophic NAD depletion in the absence of injury (54).

The second model proposes that the loss of NMNAT2 in injured axons leads to the accumulation of neurotoxic levels of NMN. In line with this model, axon degeneration can be stalled by inhibiting NamPRT while NAD levels are maintained by NAR supplementation $(68,69)$. A transgenic mouse model overexpressing E. coli NMN deamidase provided further support for this model. The degree of axonal protection in these transgenic mice was similar to those observed in $W / d_{s}$ or Sarm ${ }^{-1}$ mice and explained by the conversion of NMN to NAMN (70). However, the concept of NMN as a neurotoxic agent does not agree with the finding that increasing NamPRT expression is neuroprotective (71).

\section{Sustaining NAD levels by pharmacological agents}


Depletion of NAD is not only associated with neurodegeneration but also other pathologies including metabolic disorders $(72,73)$, heart diseases $(74,75)$, muscle atrophy $(76)$ and renal dysfunction $(77)$. Moreover, NAD levels decline with age in multiple tissues of rodents $(73,78-80)$ and humans $(81,82)$. NAD depletion is governed by two principle mechanisms - decreased NAD biosynthesis and increased NAD consumption (Figure 4).

A striking example of the deleterious physiological consequences of deficient NAD biosynthesis is pellagra, a B3 hypovitaminosis resulting from insufficient supply of dietary NAD precursors (83). NAD depletion can also be caused by reduced or impaired activity of NAD biosynthetic enzymes. For instance, NamPRT levels decrease with age $(73,84)$ and are affected in different models of heart failure $(74,75)$. Impaired QAPRT function was shown to predispose kidneys to acute injury owing to suppression of de novo NAD biosynthesis and renal NAD depletion (77).

DNA repair deficiencies implicated in neurodegenerative disorders such as xeroderma pigmentosum, ataxia-telangiectasia and Cockayne syndrome are linked to chronic PARP1 activation and increased NAD consumption (85-87). PARP1-mediated NAD depletion has also been associated with ageing due to the combined effect of reduced efficiency of the DNA repair machinery and increased levels of reactive oxygen species leading to recurring DNA lesions $(78,80)$. Furthermore, a considerable NAD decline in multiple tissues in aged mice has been linked to CD38 over-activation (88) or results from SARM1 activation in response to nerve injury, as outlined in the previous chapter (66).

Many studies using in vivo models that were aimed at boosting NAD levels either pharmacologically or by supplementation with NAD precursors, have established promising therapeutic concepts for age-related diseases (Figure 4). Pharmacological inhibition of PARP1 (89-91) or CD38 $(92,93)$ was shown to elevate NAD concentrations in several tissues. However, since these enzymes control many important signalling pathways, any pharmacological manipulation of them needs to be conducted with caution. For NAD biosynthesis enzymes, a pharmacological activator has been identified only for NamPRT. The increase in cellular NAD levels in the presence of the neuroprotective aminopropyl carbazole agent P7C3 could be attributed to the stimulation of the activity of this enzyme (94).

The concept of boosting NAD levels by dietary supplementation of NAD precursors dates back to 1937, when Conrad Elvehjem demonstrated that both Nam and NA can prevent canine pellagra (83). Dietary Nam or NA also efficiently increase the NAD content in multiple tissues of rodents (95). Nam supplementation was shown to reduce oxidative stress and inflammation in mouse models (96) and to prevent hepatosteatosis (96), acute kidney injury (77) and glaucoma (97). However, there are limitations to the use of these dietary NAD precursors. The severe flushing induced by NA results 
from activation of the G-protein-coupled receptor GPR109A (98), whereas high doses of Nam can inhibit NAD-dependent enzymes (e.g. sirtuins and PARPs).

During the last few years, a number of excellent studies have demonstrated that the supplementation with alternative NAD precursors, NR and NMN, considerably increases NAD levels and restores various physiological functions that are deteriorating in pathological conditions or during ageing. For example, both NR and NMN improve glucose metabolism and protect against obesity and type 2 diabetes $(72,73,99)$. Furthermore, these compounds induce mitochondrial biogenesis $(79,100-102)$, improve muscle $(76,79,99)$, neural $(86,103-105)$ and various other functions (for an extensive review see (106)). Dietary supplementation of NR has been associated with a slight lifespan extension in mice (107) and an increase in NAD levels in blood cells in humans $(108,109)$. Importantly and in contrast to NA, NR is well-tolerated in humans (109).

Pathological consequences of NAD depletion in tissues may be caused by a wide variety of molecular alterations ranging from failure of energy metabolism to dysfunctions of NAD-dependent signalling processes. Therefore, it is difficult to identify the exact molecular mechanisms that lead to the restoration of the physiological functions following NAD boosting therapies. Nevertheless, a growing body of evidence suggests that one of the universal mechanisms for the beneficial health effects of NAD replenishment is activation of Sirtuins $(51,73,79,86,90,102,106)$.

\section{Conclusions and perspectives}

The importance of the regulatory roles of NAD has been firmly established in several excellent studies. While impressive progress has been made regarding the mechanisms of NAD-dependent signalling, some critical questions remain unanswered. For example, NAD demand and turnover vary greatly between tissues and cell types, and, as a consequence, biosynthesis of the dinucleotide needs to be fine-tuned. However, little is known about the regulation of NAD biosynthesis and its interplay with signalling pathways. Moreover, cellular NAD biosynthesis and consumption are compartmentalised in the cell, but how these organellar NAD pools are established and maintained is not fully understood. Mitochondria are of particular interest because they represent an important hub of NAD dependent signalling and probably contain the largest intracellular NAD pool. How this pool is sustained is debated and both autonomous biosynthesis and import of the dinucleotide have been proposed.

Impaired biosynthesis and increased NAD consumption are associated with ageing and different pathologies such as degeneration of axons in injured neurons. Understanding the exact mechanism underlying the role of NAD and NMN in axonal degeneration will lead to new therapeutic concepts to 
support nerve regeneration. Increasing NAD biosynthesis by providing precursors may also be a promising therapeutic approach for other pathological states including type 2 diabetes, obesity, metabolic disorders and heart disease. Unfortunately, in the majority of the studies establishing these beneficial effects only one precursor was used, therefore it is impossible to judge the relative efficiencies of the different agents or their advantages and possible disadvantages. Moreover, the dosages used in the different studies were most often in a rather narrow range. Thereby, an important task for future research would be to establish the most efficient NAD precursor supplementation scheme and the determination of optimal dosages.

Finally, the discovery of SARM1 as a NADase and its striking role in axon degeneration has added an unexpected aspect in the understanding of NAD homeostasis. Given that another NADase, CD38, plays a critical role in age-dependent NAD decline, it appears that NADases may have a much more severe impact on the NAD metabolome as so far appreciated. Therefore, these enzymes represent attractive targets for the maintenance of physiological NAD levels.

\section{Funding}

We are grateful for funding provided by the Norway-Russia academic network building programme of the Norwegian University Centre in St. Petersburg. A.A.N. was supported by the Russian Science Foundation (Grant \# 16-14-10240). I.H. and M.Z. are supported by grants from the Norwegian Research Council (250395/F20) and the European Union's Horizon 2020 research and innovation programme under grant agreement No. 754688.

\section{References}

1. Bheda, P., Jing, H., Wolberger, C., and Lin, H. (2016) The Substrate Specificity of Sirtuins. Annu Rev Biochem 85, 405-429

2. Schiedel, M., Robaa, D., Rumpf, T., Sippl, W., and Jung, M. (2018) The Current State of NAD(+) -Dependent Histone Deacetylases (Sirtuins) as Novel Therapeutic Targets. Med Res Rev 38, 147-200

3. Masri, S. (2015) Sirtuin-dependent clock control: new advances in metabolism, aging and cancer. Curr Opin Clin Nutr Metab Care 18, 521-527

4. Tanner, K. G., Landry, J., Sternglanz, R., and Denu, J. M. (2000) Silent information regulator 2 family of NAD- dependent histone/protein deacetylases generates a unique product, 1-0acetyl-ADP-ribose. Proc Natl Acad Sci U S A 97, 14178-14182

5. Chambon, P., Weill, J. D., and Mandel, P. (1963) Nicotinamide mononucleotide activation of new DNA-dependent polyadenylic acid synthesizing nuclear enzyme. Biochem Biophys Res Commun 11, 39-43

6. Hottiger, M. O., Hassa, P. O., Luscher, B., Schuler, H., and Koch-Nolte, F. (2010) Toward a unified nomenclature for mammalian ADP-ribosyltransferases. Trends Biochem Sci 35, 208219 
7. Moss, J., Stanley, S. J., Nightingale, M. S., Murtagh, J. J., Jr., Monaco, L., Mishima, K., Chen, H. C., Williamson, K. C., and Tsai, S. C. (1992) Molecular and immunological characterization of ADP-ribosylarginine hydrolases. J Biol Chem 267, 10481-10488

8. Lin, W., Ame, J. C., Aboul-Ela, N., Jacobson, E. L., and Jacobson, M. K. (1997) Isolation and characterization of the cDNA encoding bovine poly(ADP-ribose) glycohydrolase. I Biol Chem 272, 11895-11901

9. Bai, P. (2015) Biology of Poly(ADP-Ribose) Polymerases: The Factotums of Cell Maintenance. Mol Cell 58, 947-958

10. Gupte, R., Liu, Z., and Kraus, W. L. (2017) PARPs and ADP-ribosylation: recent advances linking molecular functions to biological outcomes. Genes Dev 31, 101-126

11. Guse, A. H. (2015) Calcium mobilizing second messengers derived from NAD. Biochim Biophys Acta 1854, 1132-1137

12. Lee, H. C. (2012) Cyclic ADP-ribose and nicotinic acid adenine dinucleotide phosphate (NAADP) as messengers for calcium mobilization. J Biol Chem 287, 31633-31640

13. Sumoza-Toledo, A., and Penner, R. (2011) TRPM2: a multifunctional ion channel for calcium signalling. J Physio/ 589, 1515-1525

14. Patel, S., Marchant, J. S., and Brailoiu, E. (2010) Two-pore channels: Regulation by NAADP and customized roles in triggering calcium signals. Cell Calcium 47, 480-490

15. Galione, A. (2015) A primer of NAADP-mediated $\mathrm{Ca}(2+)$ signalling: From sea urchin eggs to mammalian cells. Cell Calcium 58, 27-47

16. Liu, L., Su, X., Quinn, W. J., 3rd, Hui, S., Krukenberg, K., Frederick, D. W., Redpath, P., Zhan, L., Chellappa, K., White, E., Migaud, M., Mitchison, T. J., Baur, J. A., and Rabinowitz, J. D. (2018) Quantitative Analysis of NAD Synthesis-Breakdown Fluxes. Cell Metab 27, 1067-1080 e1065

17. Bogan, K. L., and Brenner, C. (2008) Nicotinic acid, nicotinamide, and nicotinamide riboside: a molecular evaluation of NAD+ precursor vitamins in human nutrition. Annu Rev Nutr 28, 115130

18. Magni, G., Orsomando, G., Raffelli, N., and Ruggieri, S. (2008) Enzymology of mammalian NAD metabolism in health and disease. Front Biosci 13, 6135-6154

19. Bender, D. A. (1983) Biochemistry of tryptophan in health and disease. Mol Aspects Med 6, 101-197

20. Imai, S., and Yoshino, J. (2013) The importance of NAMPT/NAD/SIRT1 in the systemic regulation of metabolism and ageing. Diabetes Obes Metab 15 Suppl 3, 26-33

21. Bieganowski, P., and Brenner, C. (2004) Discoveries of nicotinamide riboside as a nutrient and conserved NRK genes establish a Preiss-Handler independent route to NAD+ in fungi and humans. Cell 117, 495-502

22. Preiss, J., and Handler, P. (1958) Biosynthesis of diphosphopyridine nucleotide. I. Identification of intermediates. J Biol Chem 233, 488-492

23. Houtkooper, R. H., Canto, C., Wanders, R. J., and Auwerx, J. (2010) The secret life of NAD+: an old metabolite controlling new metabolic signaling pathways. Endocr Rev 31, 194-223

24. Kulikova, V., Shabalin, K., Nerinovski, K., Dolle, C., Niere, M., Yakimov, A., Redpath, P., Khodorkovskiy, M., Migaud, M. E., Ziegler, M., and Nikiforov, A. (2015) Generation, Release, and Uptake of the NAD Precursor Nicotinic Acid Riboside by Human Cells. J Biol Chem 290, 27124-27137

25. Schwer, B., North, B. J., Frye, R. A., Ott, M., and Verdin, E. (2002) The human silent information regulator (Sir)2 homologue hSIRT3 is a mitochondrial nicotinamide adenine dinucleotide-dependent deacetylase. J Cell Biol 158, 647-657

26. Du, J., Zhou, Y., Su, X., Yu, J. J., Khan, S., Jiang, H., Kim, J., Woo, J., Kim, J. H., Choi, B. H., He, B., Chen, W., Zhang, S., Cerione, R. A., Auwerx, J., Hao, Q., and Lin, H. (2011) Sirt5 is a NADdependent protein lysine demalonylase and desuccinylase. Science 334, 806-809

27. Tan, M., Peng, C., Anderson, K. A., Chhoy, P., Xie, Z., Dai, L., Park, J., Chen, Y., Huang, H., Zhang, Y., Ro, J., Wagner, G. R., Green, M. F., Madsen, A. S., Schmiesing, J., Peterson, B. S., Xu, G., Ilkayeva, O. R., Muehlbauer, M. J., Braulke, T., Muhlhausen, C., Backos, D. S., Olsen, C. 
A., McGuire, P. J., Pletcher, S. D., Lombard, D. B., Hirschey, M. D., and Zhao, Y. (2014) Lysine glutarylation is a protein posttranslational modification regulated by SIRT5. Cell Metab 19, 605-617

28. Haigis, M. C., Mostoslavsky, R., Haigis, K. M., Fahie, K., Christodoulou, D. C., Murphy, A. J., Valenzuela, D. M., Yancopoulos, G. D., Karow, M., Blander, G., Wolberger, C., Prolla, T. A., Weindruch, R., Alt, F. W., and Guarente, L. (2006) SIRT4 inhibits glutamate dehydrogenase and opposes the effects of calorie restriction in pancreatic beta cells. Cell 126, 941-954

29. Anderson, K. A., Huynh, F. K., Fisher-Wellman, K., Stuart, J. D., Peterson, B. S., Douros, J. D., Wagner, G. R., Thompson, J. W., Madsen, A. S., Green, M. F., Sivley, R. M., Ilkayeva, O. R., Stevens, R. D., Backos, D. S., Capra, J. A., Olsen, C. A., Campbell, J. E., Muoio, D. M., Grimsrud, P. A., and Hirschey, M. D. (2017) SIRT4 is a Lysine Deacylase that Controls Leucine Metabolism and Insulin Secretion. Cell Metab 25, 838-855 e815

30. Mathias, R. A., Greco, T. M., Oberstein, A., Budayeva, H. G., Chakrabarti, R., Rowland, E. A., Kang, Y., Shenk, T., and Cristea, I. M. (2014) Sirtuin 4 is a lipoamidase regulating pyruvate dehydrogenase complex activity. Cell 159, 1615-1625

31. Dolle, C., Niere, M., Lohndal, E., and Ziegler, M. (2010) Visualization of subcellular NAD pools and intra-organellar protein localization by poly-ADP-ribose formation. Cell Mol Life Sci 67, 433-443

32. Schweiger, M., Hennig, K., Lerner, F., Niere, M., Hirsch-Kauffmann, M., Specht, T., Weise, C., Oei, S. L., and Ziegler, M. (2001) Characterization of recombinant human nicotinamide mononucleotide adenylyl transferase (NMNAT), a nuclear enzyme essential for NAD synthesis. FEBS Lett 492, 95-100

33. Berger, F., Lau, C., Dahlmann, M., and Ziegler, M. (2005) Subcellular compartmentation and differential catalytic properties of the three human nicotinamide mononucleotide adenylyltransferase isoforms. J Biol Chem 280, 36334-36341

34. Lau, C., Dolle, C., Gossmann, T. I., Agledal, L., Niere, M., and Ziegler, M. (2010) Isoformspecific targeting and interaction domains in human nicotinamide mononucleotide adenylyltransferases. J Biol Chem 285, 18868-18876

35. Mayer, P. R., Huang, N., Dewey, C. M., Dries, D. R., Zhang, H., and Yu, G. (2010) Expression, localization, and biochemical characterization of nicotinamide mononucleotide adenylyltransferase 2. J Biol Chem 285, 40387-40396

36. Nikiforov, A., Dolle, C., Niere, M., and Ziegler, M. (2011) Pathways and subcellular compartmentation of NAD biosynthesis in human cells: from entry of extracellular precursors to mitochondrial NAD generation. J Biol Chem 286, 21767-21778

37. Davila, A., Liu, L., Chellappa, K., Redpath, P., Nakamaru-Ogiso, E., Paolella, L. M., Zhang, Z., Migaud, M. E., Rabinowitz, J. D., and Baur, J. A. (2018) Nicotinamide adenine dinucleotide is transported into mammalian mitochondria. Elife 7

38. Hikosaka, K., Ikutani, M., Shito, M., Kazuma, K., Gulshan, M., Nagai, Y., Takatsu, K., Konno, K., Tobe, K., Kanno, H., and Nakagawa, T. (2014) Deficiency of nicotinamide mononucleotide adenylyltransferase 3 (nmnat3) causes hemolytic anemia by altering the glycolytic flow in mature erythrocytes. J Biol Chem 289, 14796-14811

39. Gulshan, M., Yaku, K., Okabe, K., Mahmood, A., Sasaki, T., Yamamoto, M., Hikosaka, K., Usui, I., Kitamura, T., Tobe, K., and Nakagawa, T. (2018) Overexpression of Nmnat3 efficiently increases NAD and NGD levels and ameliorates age-associated insulin resistance. Aging Cell, e12798

40. Yamamoto, M., Hikosaka, K., Mahmood, A., Tobe, K., Shojaku, H., Inohara, H., and Nakagawa, T. (2016) Nmnat3 Is Dispensable in Mitochondrial NAD Level Maintenance In Vivo. PLoS One 11, e0147037

41. Todisco, S., Agrimi, G., Castegna, A., and Palmieri, F. (2006) Identification of the mitochondrial NAD+ transporter in Saccharomyces cerevisiae. J Biol Chem 281, 1524-1531

42. Palmieri, F., Rieder, B., Ventrella, A., Blanco, E., Do, P. T., Nunes-Nesi, A., Trauth, A. U., Fiermonte, G., Tjaden, J., Agrimi, G., Kirchberger, S., Paradies, E., Fernie, A. R., and Neuhaus, 
H. E. (2009) Molecular identification and functional characterization of Arabidopsis thaliana mitochondrial and chloroplastic NAD+ carrier proteins. J Biol Chem 284, 31249-31259

43. Cambronne, X. A., Stewart, M. L., Kim, D., Jones-Brunette, A. M., Morgan, R. K., Farrens, D. L., Cohen, M. S., and Goodman, R. H. (2016) Biosensor reveals multiple sources for mitochondrial $\operatorname{NAD}(+)$. Science 352, 1474-1477

44. Agrimi, G., Russo, A., Scarcia, P., and Palmieri, F. (2012) The human gene SLC25A17 encodes a peroxisomal transporter of coenzyme A, FAD and NAD+. Biochem J 443, 241-247

45. Conforti, L., Janeckova, L., Wagner, D., Mazzola, F., Cialabrini, L., Di Stefano, M., Orsomando, G., Magni, G., Bendotti, C., Smyth, N., and Coleman, M. (2011) Reducing expression of NAD+ synthesizing enzyme NMNAT1 does not affect the rate of Wallerian degeneration. FEBS J 278, 2666-2679

46. Gilley, J., Adalbert, R., Yu, G., and Coleman, M. P. (2013) Rescue of peripheral and CNS axon defects in mice lacking NMNAT2. J Neurosci 33, 13410-13424

47. Ryu, K. W., Nandu, T., Kim, J., Challa, S., DeBerardinis, R. J., and Kraus, W. L. (2018) Metabolic regulation of transcription through compartmentalized NAD(+) biosynthesis. Science $\mathbf{3 6 0}$

48. Wang, J., Zhai, Q., Chen, Y., Lin, E., Gu, W., McBurney, M. W., and He, Z. (2005) A local mechanism mediates NAD-dependent protection of axon degeneration. J Cell Biol 170, 349355

49. Gerdts, J., Summers, D. W., Milbrandt, J., and DiAntonio, A. (2016) Axon Self-Destruction: New Links among SARM1, MAPKs, and NAD+ Metabolism. Neuron 89, 449-460

50. Coleman, M. P., and Freeman, M. R. (2010) Wallerian degeneration, wld(s), and nmnat. Annu Rev Neurosci 33, 245-267

51. Araki, T., Sasaki, Y., and Milbrandt, J. (2004) Increased nuclear NAD biosynthesis and SIRT1 activation prevent axonal degeneration. Science 305, 1010-1013

52. Beirowski, B., Babetto, E., Gilley, J., Mazzola, F., Conforti, L., Janeckova, L., Magni, G., Ribchester, R. R., and Coleman, M. P. (2009) Non-nuclear Wld(S) determines its neuroprotective efficacy for axons and synapses in vivo. J Neurosci 29, 653-668

53. Babetto, E., Beirowski, B., Janeckova, L., Brown, R., Gilley, J., Thomson, D., Ribchester, R. R., and Coleman, M. P. (2010) Targeting NMNAT1 to axons and synapses transforms its neuroprotective potency in vivo. J Neurosci 30, 13291-13304

54. Gerdts, J., Brace, E. J., Sasaki, Y., DiAntonio, A., and Milbrandt, J. (2015) SARM1 activation triggers axon degeneration locally via $N A D(+)$ destruction. Science 348, 453-457

55. Gilley, J., and Coleman, M. P. (2010) Endogenous Nmnat2 is an essential survival factor for maintenance of healthy axons. PLOS Biol 8, e1000300

56. Hicks, A. N., Lorenzetti, D., Gilley, J., Lu, B., Andersson, K. E., Miligan, C., Overbeek, P. A., Oppenheim, R., and Bishop, C. E. (2012) Nicotinamide mononucleotide adenylyltransferase 2 (Nmnat2) regulates axon integrity in the mouse embryo. PLoS One 7, e47869

57. Ferri, A., Sanes, J. R., Coleman, M. P., Cunningham, J. M., and Kato, A. C. (2003) Inhibiting axon degeneration and synapse loss attenuates apoptosis and disease progression in a mouse model of motoneuron disease. Curr Biol 13, 669-673

58. Howell, G. R., Libby, R. T., Jakobs, T. C., Smith, R. S., Phalan, F. C., Barter, J. W., Barbay, J. M., Marchant, J. K., Mahesh, N., Porciatti, V., Whitmore, A. V., Masland, R. H., and John, S. W. (2007) Axons of retinal ganglion cells are insulted in the optic nerve early in DBA/2J glaucoma. J Cell Biol 179, 1523-1537

59. Sajadi, A., Schneider, B. L., and Aebischer, P. (2004) Wlds-mediated protection of dopaminergic fibers in an animal model of Parkinson disease. Curr Biol 14, 326-330

60. Ljungberg, M. C., Ali, Y. O., Zhu, J., Wu, C. S., Oka, K., Zhai, R. G., and Lu, H. C. (2012) CREBactivity and nmnat2 transcription are down-regulated prior to neurodegeneration, while NMNAT2 over-expression is neuroprotective, in a mouse model of human tauopathy. Hum Mol Genet 21, 251-267

61. Ali, Y. O., Allen, H. M., Yu, L., Li-Kroeger, D., Bakhshizadehmahmoudi, D., Hatcher, A., McCabe, C., Xu, J., Bjorklund, N., Taglialatela, G., Bennett, D. A., De Jager, P. L., Shulman, J. 
M., Bellen, H. J., and Lu, H. C. (2016) NMNAT2:HSP90 Complex Mediates Proteostasis in Proteinopathies. PLoS Biol 14, e1002472

62. Gilley, J., Ribchester, R. R., and Coleman, M. P. (2017) Sarm1 Deletion, but Not WId(S), Confers Lifelong Rescue in a Mouse Model of Severe Axonopathy. Cell Rep 21, 10-16

63. Sasaki, Y., Nakagawa, T., Mao, X., DiAntonio, A., and Milbrandt, J. (2016) NMNAT1 inhibits axon degeneration via blockade of SARM1-mediated NAD(+) depletion. Elife $\mathbf{5}$

64. Henninger, N., Bouley, J., Sikoglu, E. M., An, J., Moore, C. M., King, J. A., Bowser, R., Freeman, M. R., and Brown, R. H., Jr. (2016) Attenuated traumatic axonal injury and improved functional outcome after traumatic brain injury in mice lacking Sarm1. Brain 139, 1094-1105

65. Geisler, S., Doan, R. A., Strickland, A., Huang, X., Milbrandt, J., and DiAntonio, A. (2016) Prevention of vincristine-induced peripheral neuropathy by genetic deletion of SARM1 in mice. Brain 139, 3092-3108

66. Essuman, K., Summers, D. W., Sasaki, Y., Mao, X., DiAntonio, A., and Milbrandt, J. (2017) The SARM1 Toll/Interleukin-1 Receptor Domain Possesses Intrinsic NAD(+) Cleavage Activity that Promotes Pathological Axonal Degeneration. Neuron 93, 1334-1343 e1335

67. Essuman, K., Summers, D. W., Sasaki, Y., Mao, X., Yim, A. K. Y., DiAntonio, A., and Milbrandt, J. (2018) TIR Domain Proteins Are an Ancient Family of NAD(+)-Consuming Enzymes. Curr Biol 28, 421-430 e424

68. Di Stefano, M., Nascimento-Ferreira, I., Orsomando, G., Mori, V., Gilley, J., Brown, R., Janeckova, L., Vargas, M. E., Worrell, L. A., Loreto, A., Tickle, J., Patrick, J., Webster, J. R., Marangoni, M., Carpi, F. M., Pucciarelli, S., Rossi, F., Meng, W., Sagasti, A., Ribchester, R. R., Magni, G., Coleman, M. P., and Conforti, L. (2015) A rise in NAD precursor nicotinamide mononucleotide (NMN) after injury promotes axon degeneration. Cell Death Differ 22, 731742

69. Liu, H. W., Smith, C. B., Schmidt, M. S., Cambronne, X. A., Cohen, M. S., Migaud, M. E., Brenner, C., and Goodman, R. H. (2018) Pharmacological bypass of NAD(+) salvage pathway protects neurons from chemotherapy-induced degeneration. Proc Natl Acad Sci U S A

70. Di Stefano, M., Loreto, A., Orsomando, G., Mori, V., Zamporlini, F., Hulse, R. P., Webster, J., Donaldson, L. F., Gering, M., Raffaelli, N., Coleman, M. P., Gilley, J., and Conforti, L. (2017) NMN Deamidase Delays Wallerian Degeneration and Rescues Axonal Defects Caused by NMNAT2 Deficiency In Vivo. Curr Biol 27, 784-794

71. Sasaki, Y., Araki, T., and Milbrandt, J. (2006) Stimulation of nicotinamide adenine dinucleotide biosynthetic pathways delays axonal degeneration after axotomy. J Neurosci 26, 8484-8491

72. Trammell, S. A., Weidemann, B. J., Chadda, A., Yorek, M. S., Holmes, A., Coppey, L. J., Obrosov, A., Kardon, R. H., Yorek, M. A., and Brenner, C. (2016) Nicotinamide Riboside Opposes Type 2 Diabetes and Neuropathy in Mice. Sci Rep 6, 26933

73. Yoshino, J., Mills, K. F., Yoon, M. J., and Imai, S. (2011) Nicotinamide mononucleotide, a key $\mathrm{NAD}(+)$ intermediate, treats the pathophysiology of diet- and age-induced diabetes in mice. Cell Metab 14, 528-536

74. Hsu, C. P., Oka, S., Shao, D., Hariharan, N., and Sadoshima, J. (2009) Nicotinamide phosphoribosyltransferase regulates cell survival through NAD+ synthesis in cardiac myocytes. Circ Res 105, 481-491

75. Diguet, N., Trammell, S. A. J., Tannous, C., Deloux, R., Piquereau, J., Mougenot, N., Gouge, A., Gressette, M., Manoury, B., Blanc, J., Breton, M., Decaux, J. F., Lavery, G. G., Baczko, I., Zoll, J., Garnier, A., Li, Z., Brenner, C., and Mericskay, M. (2018) Nicotinamide Riboside Preserves Cardiac Function in a Mouse Model of Dilated Cardiomyopathy. Circulation 137, 2256-2273

76. Ryu, D., Zhang, H., Ropelle, E. R., Sorrentino, V., Mazala, D. A., Mouchiroud, L., Marshall, P. L., Campbell, M. D., Ali, A. S., Knowels, G. M., Bellemin, S., Iyer, S. R., Wang, X., Gariani, K., Sauve, A. A., Canto, C., Conley, K. E., Walter, L., Lovering, R. M., Chin, E. R., Jasmin, B. J., Marcinek, D. J., Menzies, K. J., and Auwerx, J. (2016) NAD+ repletion improves muscle function in muscular dystrophy and counters global PARylation. Sci Transl Med 8, 361ra139 
77. Poyan Mehr, A., Tran, M. T., Ralto, K. M., Leaf, D. E., Washco, V., Messmer, J., Lerner, A., Kher, A., Kim, S. H., Khoury, C. C., Herzig, S. J., Trovato, M. E., Simon-Tillaux, N., Lynch, M. R., Thadhani, R. I., Clish, C. B., Khabbaz, K. R., Rhee, E. P., Waikar, S. S., Berg, A. H., and Parikh, S. M. (2018) De novo NAD(+) biosynthetic impairment in acute kidney injury in humans. Nat Med 24, 1351-1359

78. Braidy, N., Guillemin, G. J., Mansour, H., Chan-Ling, T., Poljak, A., and Grant, R. (2011) Age related changes in NAD+ metabolism oxidative stress and Sirt1 activity in wistar rats. PLoS One 6, e19194

79. Gomes, A. P., Price, N. L., Ling, A. J., Moslehi, J. J., Montgomery, M. K., Rajman, L., White, J. P., Teodoro, J. S., Wrann, C. D., Hubbard, B. P., Mercken, E. M., Palmeira, C. M., de Cabo, R., Rolo, A. P., Turner, N., Bell, E. L., and Sinclair, D. A. (2013) Declining NAD(+) induces a pseudohypoxic state disrupting nuclear-mitochondrial communication during aging. Cell 155, 1624-1638

80. Mouchiroud, L., Houtkooper, R. H., Moullan, N., Katsyuba, E., Ryu, D., Canto, C., Mottis, A., Jo, Y. S., Viswanathan, M., Schoonjans, K., Guarente, L., and Auwerx, J. (2013) The $\mathrm{NAD}(+) /$ Sirtuin Pathway Modulates Longevity through Activation of Mitochondrial UPR and FOXO Signaling. Cell 154, 430-441

81. Zhu, X. H., Lu, M., Lee, B. Y., Ugurbil, K., and Chen, W. (2015) In vivo NAD assay reveals the intracellular NAD contents and redox state in healthy human brain and their age dependences. Proc Natl Acad Sci U S A 112, 2876-2881

82. Massudi, H., Grant, R., Braidy, N., Guest, J., Farnsworth, B., and Guillemin, G. J. (2012) Ageassociated changes in oxidative stress and NAD+ metabolism in human tissue. PLoS One 7, e42357

83. Elvehjem CA, M. R., Strong FM, Woolley DW. (1938) The isolation and identification of the anti-black tongue factor. J. Biol. Chem. 123, 137-149

84. Stein, L. R., and Imai, S. (2014) Specific ablation of Nampt in adult neural stem cells recapitulates their functional defects during aging. EMBO J 33, 1321-1340

85. Fang, E. F., Scheibye-Knudsen, M., Brace, L. E., Kassahun, H., SenGupta, T., Nilsen, H., Mitchell, J. R., Croteau, D. L., and Bohr, V. A. (2014) Defective mitophagy in XPA via PARP-1 hyperactivation and NAD(+)/SIRT1 reduction. Cell 157, 882-896

86. Brown, K. D., Maqsood, S., Huang, J. Y., Pan, Y., Harkcom, W., Li, W., Sauve, A., Verdin, E., and Jaffrey, S. R. (2014) Activation of SIRT3 by the NAD(+) precursor nicotinamide riboside protects from noise-induced hearing loss. Cell Metab 20, 1059-1068

87. Scheibye-Knudsen, M., Mitchell, S. J., Fang, E. F., Iyama, T., Ward, T., Wang, J., Dunn, C. A., Singh, N., Veith, S., Hasan-Olive, M. M., Mangerich, A., Wilson, M. A., Mattson, M. P., Bergersen, L. H., Cogger, V. C., Warren, A., Le Couteur, D. G., Moaddel, R., Wilson, D. M., 3rd, Croteau, D. L., de Cabo, R., and Bohr, V. A. (2014) A high-fat diet and NAD(+) activate Sirt1 to rescue premature aging in cockayne syndrome. Cell Metab 20, 840-855

88. Camacho-Pereira, J., Tarrago, M. G., Chini, C. C. S., Nin, V., Escande, C., Warner, G. M., Puranik, A. S., Schoon, R. A., Reid, J. M., Galina, A., and Chini, E. N. (2016) CD38 Dictates AgeRelated NAD Decline and Mitochondrial Dysfunction through an SIRT3-Dependent Mechanism. Cell Metab 23, 1127-1139

89. Gariani, K., Ryu, D., Menzies, K. J., Yi, H. S., Stein, S., Zhang, H., Perino, A., Lemos, V., Katsyuba, E., Jha, P., Vijgen, S., Rubbia-Brandt, L., Kim, Y. K., Kim, J. T., Kim, K. S., Shong, M., Schoonjans, K., and Auwerx, J. (2017) Inhibiting poly ADP-ribosylation increases fatty acid oxidation and protects against fatty liver disease. J Hepatol 66, 132-141

90. Bai, P., Canto, C., Oudart, H., Brunyanszki, A., Cen, Y., Thomas, C., Yamamoto, H., Huber, A., Kiss, B., Houtkooper, R. H., Schoonjans, K., Schreiber, V., Sauve, A. A., Menissier-de Murcia, J., and Auwerx, J. (2011) PARP-1 inhibition increases mitochondrial metabolism through SIRT1 activation. Cell Metab 13, 461-468

91. Mukhopadhyay, P., Horvath, B., Rajesh, M., Varga, Z. V., Gariani, K., Ryu, D., Cao, Z., Holovac, E., Park, O., Zhou, Z., Xu, M. J., Wang, W., Godlewski, G., Paloczi, J., Nemeth, B. T., Persidsky, 
Y., Liaudet, L., Hasko, G., Bai, P., Boulares, A. H., Auwerx, J., Gao, B., and Pacher, P. (2017) PARP inhibition protects against alcoholic and non-alcoholic steatohepatitis. J Hepatol 66, 589-600

92. Escande, C., Nin, V., Price, N. L., Capellini, V., Gomes, A. P., Barbosa, M. T., O'Neil, L., White, T. A., Sinclair, D. A., and Chini, E. N. (2013) Flavonoid apigenin is an inhibitor of the NAD+ ase CD38: implications for cellular NAD+ metabolism, protein acetylation, and treatment of metabolic syndrome. Diabetes 62, 1084-1093

93. Haffner, C. D., Becherer, J. D., Boros, E. E., Cadilla, R., Carpenter, T., Cowan, D., Deaton, D. N., Guo, Y., Harrington, W., Henke, B. R., Jeune, M. R., Kaldor, I., Milliken, N., Petrov, K. G., Preugschat, F., Schulte, C., Shearer, B. G., Shearer, T., Smalley, T. L., Jr., Stewart, E. L., Stuart, J. D., and Ulrich, J. C. (2015) Discovery, Synthesis, and Biological Evaluation of Thiazoloquin(az)olin(on)es as Potent CD38 Inhibitors. J Med Chem 58, 3548-3571

94. Wang, G., Han, T., Nijhawan, D., Theodoropoulos, P., Naidoo, J., Yadavalli, S., Mirzaei, H., Pieper, A. A., Ready, J. M., and McKnight, S. L. (2014) P7C3 neuroprotective chemicals function by activating the rate-limiting enzyme in NAD salvage. Cell 158, 1324-1334

95. Jackson, T. M., Rawling, J. M., Roebuck, B. D., and Kirkland, J. B. (1995) Large supplements of nicotinic acid and nicotinamide increase tissue NAD+ and poly(ADP-ribose) levels but do not affect diethylnitrosamine-induced altered hepatic foci in Fischer-344 rats. J Nutr 125, 14551461

96. Mitchell, S. J., Bernier, M., Aon, M. A., Cortassa, S., Kim, E. Y., Fang, E. F., Palacios, H. H., Ali, A., Navas-Enamorado, I., Di Francesco, A., Kaiser, T. A., Waltz, T. B., Zhang, N., Ellis, J. L., Elliott, P. J., Frederick, D. W., Bohr, V. A., Schmidt, M. S., Brenner, C., Sinclair, D. A., Sauve, A. A., Baur, J. A., and de Cabo, R. (2018) Nicotinamide Improves Aspects of Healthspan, but Not Lifespan, in Mice. Cell Metab 27, 667-676 e664

97. Williams, P. A., Harder, J. M., Foxworth, N. E., Cochran, K. E., Philip, V. M., Porciatti, V., Smithies, O., and John, S. W. (2017) Vitamin B3 modulates mitochondrial vulnerability and prevents glaucoma in aged mice. Science $355,756-760$

98. Benyo, Z., Gille, A., Bennett, C. L., Clausen, B. E., and Offermanns, S. (2006) Nicotinic acidinduced flushing is mediated by activation of epidermal langerhans cells. Mol Pharmacol 70, 1844-1849

99. Canto, C., Houtkooper, R. H., Pirinen, E., Youn, D. Y., Oosterveer, M. H., Cen, Y., FernandezMarcos, P. J., Yamamoto, H., Andreux, P. A., Cettour-Rose, P., Gademann, K., Rinsch, C., Schoonjans, K., Sauve, A. A., and Auwerx, J. (2012) The NAD(+) precursor nicotinamide riboside enhances oxidative metabolism and protects against high-fat diet-induced obesity. Cell Metab 15, 838-847

100. Mills, K. F., Yoshida, S., Stein, L. R., Grozio, A., Kubota, S., Sasaki, Y., Redpath, P., Migaud, M. E., Apte, R. S., Uchida, K., Yoshino, J., and Imai, S. I. (2016) Long-Term Administration of Nicotinamide Mononucleotide Mitigates Age-Associated Physiological Decline in Mice. Cell Metab 24, 795-806

101. Khan, N. A., Auranen, M., Paetau, I., Pirinen, E., Euro, L., Forsstrom, S., Pasila, L., Velagapudi, V., Carroll, C. J., Auwerx, J., and Suomalainen, A. (2014) Effective treatment of mitochondrial myopathy by nicotinamide riboside, a vitamin B3. EMBO Mol Med 6, 721-731

102. Cerutti, R., Pirinen, E., Lamperti, C., Marchet, S., Sauve, A. A., Li, W., Leoni, V., Schon, E. A., Dantzer, F., Auwerx, J., Viscomi, C., and Zeviani, M. (2014) NAD(+)-dependent activation of Sirt1 corrects the phenotype in a mouse model of mitochondrial disease. Cell Metab 19, 1042-1049

103. Fang, E. F., Kassahun, H., Croteau, D. L., Scheibye-Knudsen, M., Marosi, K., Lu, H., Shamanna, R. A., Kalyanasundaram, S., Bollineni, R. C., Wilson, M. A., Iser, W. B., Wollman, B. N., Morevati, M., Li, J., Kerr, J. S., Lu, Q., Waltz, T. B., Tian, J., Sinclair, D. A., Mattson, M. P., Nilsen, H., and Bohr, V. A. (2016) NAD(+) Replenishment Improves Lifespan and Healthspan in Ataxia Telangiectasia Models via Mitophagy and DNA Repair. Cell Metab 24, 566-581 
104. Gong, B., Pan, Y., Vempati, P., Zhao, W., Knable, L., Ho, L., Wang, J., Sastre, M., Ono, K., Sauve, A. A., and Pasinetti, G. M. (2013) Nicotinamide riboside restores cognition through an upregulation of proliferator-activated receptor-gamma coactivator 1alpha regulated betasecretase 1 degradation and mitochondrial gene expression in Alzheimer's mouse models. Neurobiol Aging 34, 1581-1588

105. Park, J. H., Long, A., Owens, K., and Kristian, T. (2016) Nicotinamide mononucleotide inhibits post-ischemic $\mathrm{NAD}(+)$ degradation and dramatically ameliorates brain damage following global cerebral ischemia. Neurobiol Dis 95, 102-110

106. Yoshino, J., Baur, J. A., and Imai, S. I. (2018) NAD(+) Intermediates: The Biology and Therapeutic Potential of NMN and NR. Cell Metab 27, 513-528

107. Zhang, H., Ryu, D., Wu, Y., Gariani, K., Wang, X., Luan, P., D'Amico, D., Ropelle, E. R., Lutolf, M. P., Aebersold, R., Schoonjans, K., Menzies, K. J., and Auwerx, J. (2016) NAD(+) repletion improves mitochondrial and stem cell function and enhances life span in mice. Science $\mathbf{3 5 2}$, 1436-1443

108. Martens, C. R., Denman, B. A., Mazzo, M. R., Armstrong, M. L., Reisdorph, N., McQueen, M. B., Chonchol, M., and Seals, D. R. (2018) Chronic nicotinamide riboside supplementation is well-tolerated and elevates $\operatorname{NAD}(+)$ in healthy middle-aged and older adults. Nat Commun 9, 1286

109. Trammell, S. A., Schmidt, M. S., Weidemann, B. J., Redpath, P., Jaksch, F., Dellinger, R. W., Li, Z., Abel, E. D., Migaud, M. E., and Brenner, C. (2016) Nicotinamide riboside is uniquely and orally bioavailable in mice and humans. Nat Commun 7, 12948 


\section{Figure legends}

Figure 1. Metabolism of NAD in humans. NAD biosynthesis requires two major steps, the first comprises mononucleotide formation of NMN or NAMN catalysed by phosphoribosyltransferases (PRTs) specific for nicotinamide (Nam), nicotinic acid (NA) or quinolinic acid (QA) and by nicotinamide riboside kinases (NRKs) phosphorylating both nicotinamide riboside (NR) and nicotinic acid riboside (NAR). The second step is dinucleotide generation via condensation of NMN/NAMN with the AMP moiety of ATP by nicotinamide mononucleotide adenylyltransferases (NMNATs). Mononucleotide precursors are collectively referred to as vitamin B3 except for QA which is a product of tryptophan catabolism. NAD formation from NAMN requires amidation of nicotinic acid adenine dinucleotide (NAAD) by NAD synthetase (NADS). Phosphorylation of NAD by NAD kinase (NADK) leads to generation of NADP. NAD and NADP partake in redox reactions, where they are reversibly reduced to NADH and NADPH. NAD is consumed by mono- and poly-ADP-ribosylation catalysed by members of the PARP/ARTD family of proteins, by sirtuin mediated protein deacylation leading to the release of $O$-acylated-ADP-ribose (OAADPR) and by synthesis of the calcium releasing second messengers cyclic ADP-ribose (CADPR), ADP-ribose (ADPR) and nicotinic acid adenine dinucleotide phosphate (NAADP). Release of nicotinamide is common to all NAD-consuming processes, and nicotinamide salvage through NamPRT therefore constitutes the most important NAD biosynthetic route.

Figure 2. Compartmentalisation of NAD metabolism and biosynthesis. All NAD biosynthetic enzymes involved in the formation of the pyridine mononucleotides NMN and NAMN display nuclear-cytosolic localisation (exemplified for NamPRT), whereas three isozymes of NMNAT localise to the nucleus (NMNAT1), the mitochondria (NMNAT3) and the Golgi apparatus facing towards the cytosol (NMNAT2). Localisation of major NAD consuming reactions carried out by, for instance, members of the Sirtuin and PARP family of proteins overlaps with those found for NMNATs. The role of NMNAT3 in mitochondrial NAD biosynthesis is elusive. For NMNAT3-dependent mitochondrial NAD biosynthesis, the apparent absence of mitochondrial NMN producing enzymes requires the presence of a hitherto unknown NMN transporter. An NMNAT3-independent route for mitochondrial NAD demands for the existence of a hitherto unidentified NAD carrier. Evidence for NAD transport across a biological membrane has so far been provided only for peroxisomes. Pyridine nucleotides are supposed to be freely exchangeable between the nucleus and the cytosol, however, substrate competition between nuclear NMNAT1 and cytosolic NMNAT2 may regulate NAD availability in these two compartments.

Figure 3. The role of NAD metabolism in maintaining axonal integrity. (A) In healthy neurons, NMNAT2 is transported to the distal nerve ends and maintains NAD levels. (B) Upon axotomy, NMNAT2 is rapidly degraded. The subsequent loss of axonal integrity is currently explained by two models: According to the first model, induction of SARM1 NAD glycohydrolase activity leads to catastrophic NAD depletion, whereas the second model suggests NMN accumulation to be neurotoxic. Supporting evidence for these models has been provided by the following observations: Degeneration of injured axons is delayed by (C) expression of $W / d_{s}$ encoding a mutant protein composed of full length NMNAT1 fused to an N-terminal portion of the ubiquitin ligase Ufd2a, (D) knockout of Sarm1, (E) heterologous expression of E. coli NMN deamidase, and (F) supplying nerve cells with a combination of the NamPRT inhibitor FK866 and NAR, an NAD precursor that is not dependent on NamPRT activity. 
Figure 4. Sustaining NAD levels by pharmacological agents. Tissue NAD levels decrease with ageing and under various pathological conditions. NAD depletion can be the result of decreased NAD biosynthesis, dietary deficiency of NAD precursors, inhibition of NAD biosynthetic enzymes, and chronic activation of $\mathrm{NAD}^{+}$consuming enzymes (e.g. PARP1, CD38 and SARM1). Several concepts have been developed aimed at sustaining NAD levels using pharmacological agents. These include inhibitors of NAD-consuming enzymes PARP1 and CD38, activators of NAD biosynthetic enzymes such as NamPRT, as well as supplementation with NAD precursors (e.g. NA, NAM, NR or NMN). Stimulation of sirtuin activity by NAD replenishment is one of the universal mechanisms responsible for the beneficial health effects 
NAD biosynthesis

NAD-dependent signalling

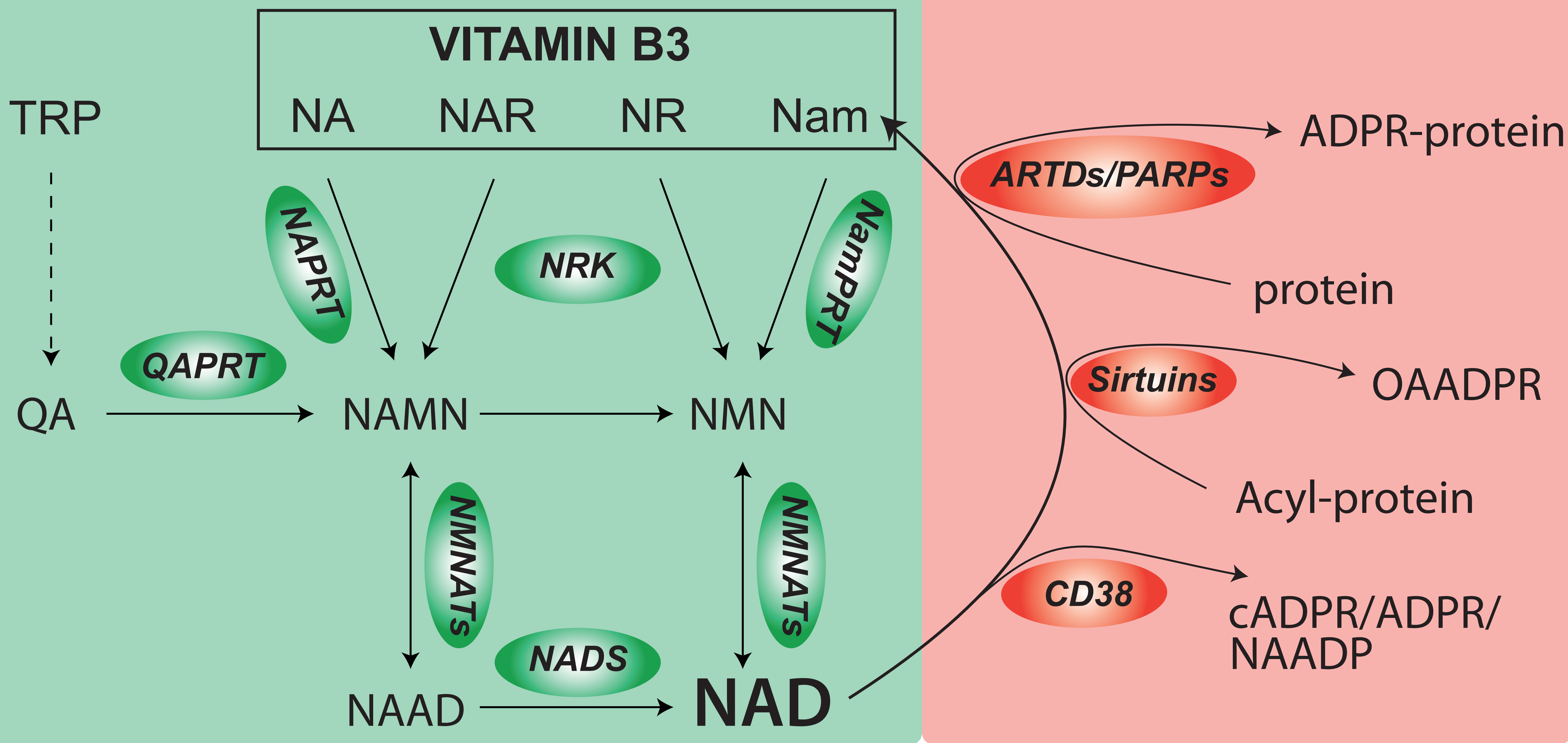

NAD dependent redox reactions

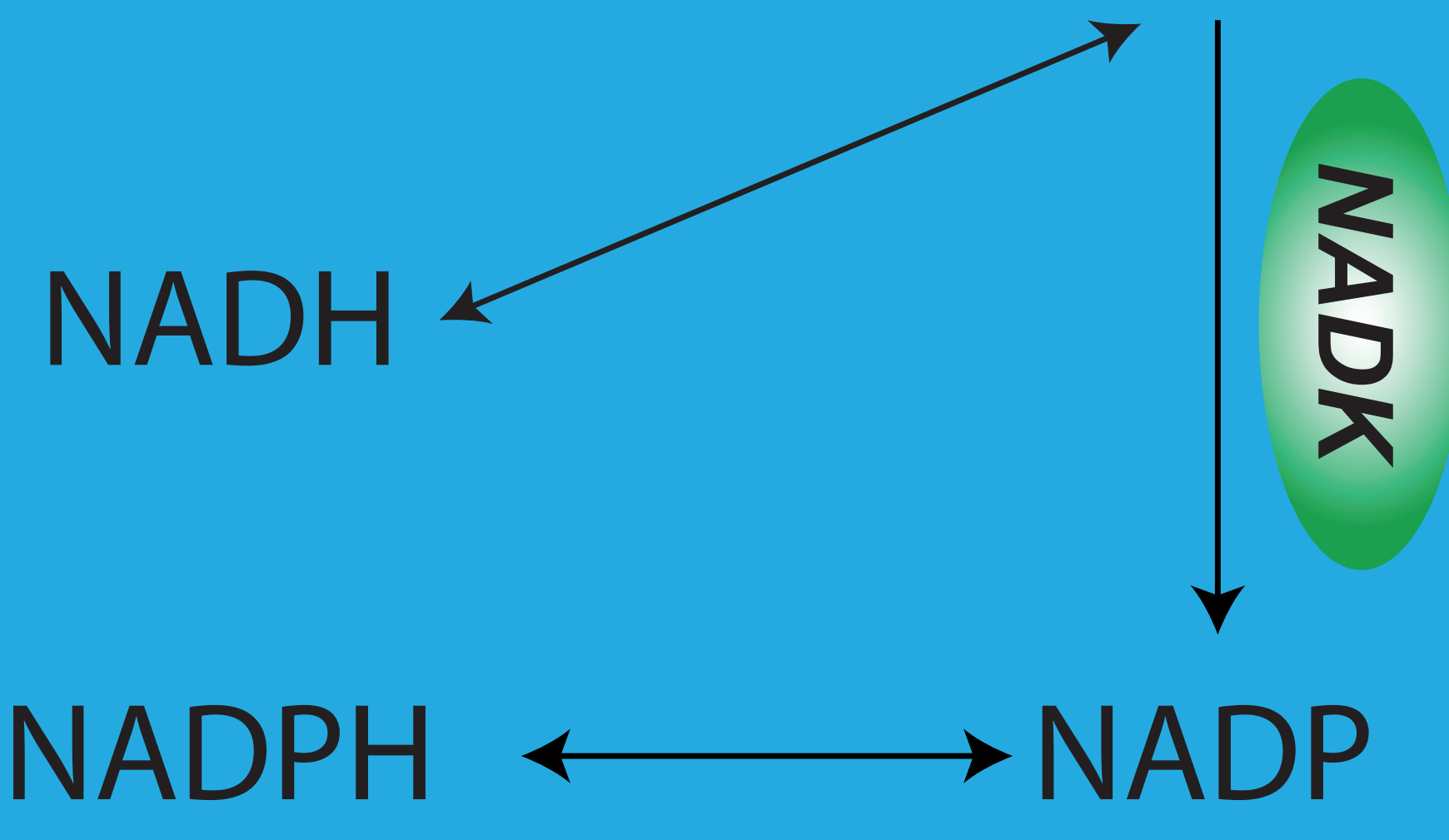




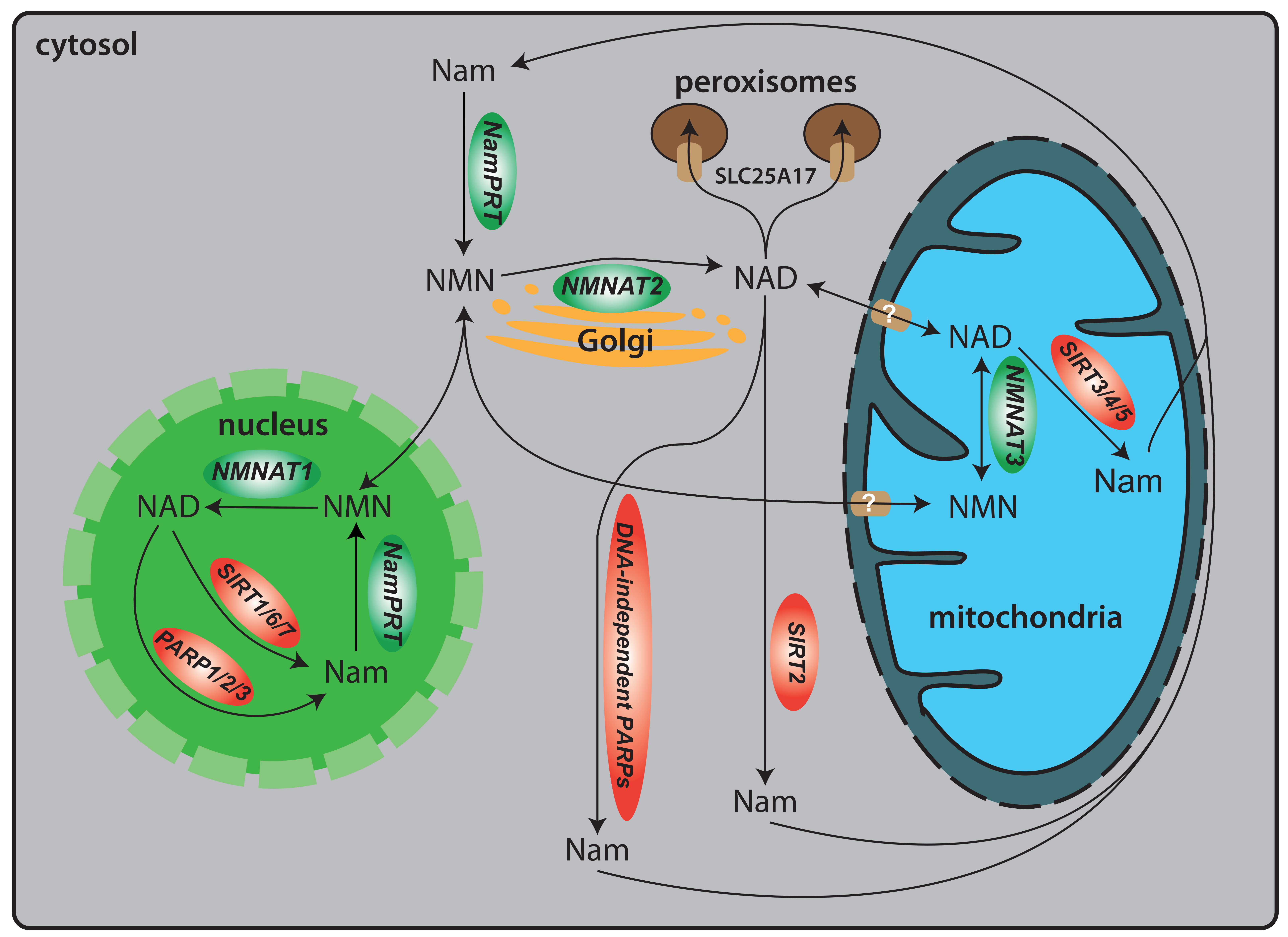



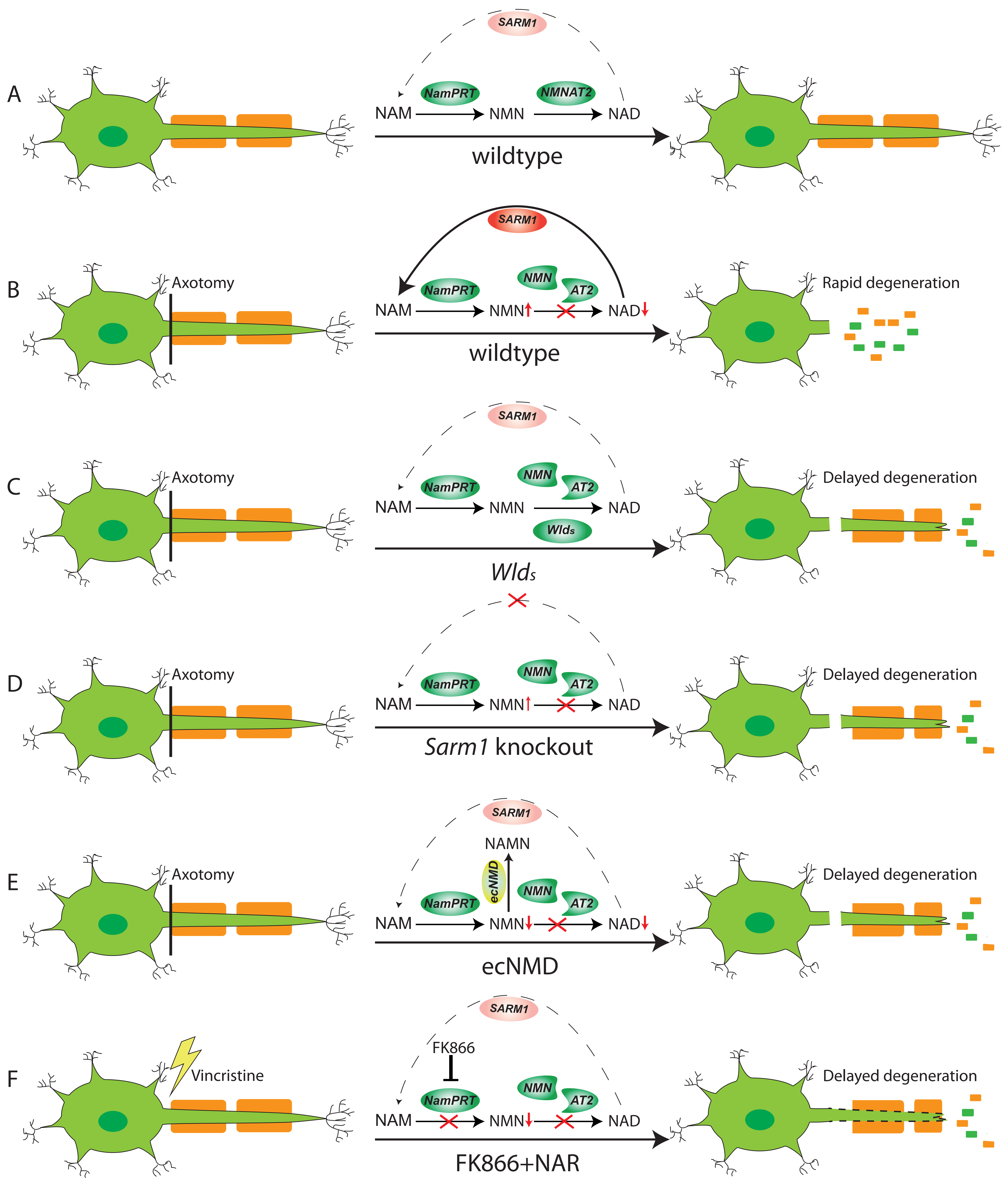


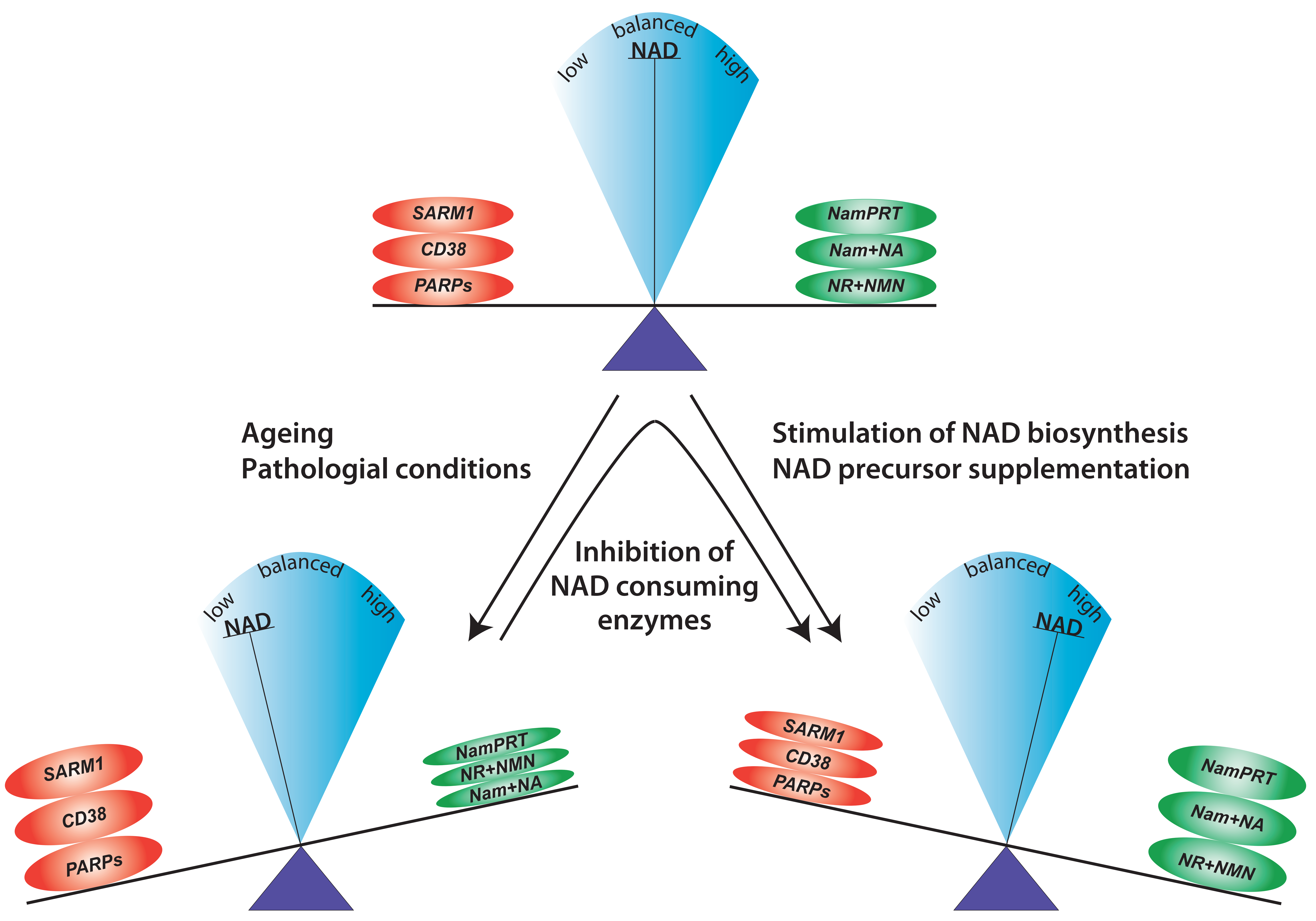

